\title{
Using Environmental Physiology to Teach Physiological Regulation
}

\author{
Shawn R. Simonson
}

check for

updates

Citation: Simonson, S.R. Using

Environmental Physiology to Teach Physiological Regulation. Educ. Sci. 2022, 12, 6. https://doi.org/10.3390/ educsci12010006

Academic Editor: Eila Jeronen

Received: 2 November 2021

Accepted: 17 December 2021

Published: 24 December 2021

Publisher's Note: MDPI stays neutral with regard to jurisdictional claims in published maps and institutional affiliations.

Copyright: (C) 2021 by the author. Licensee MDPI, Basel, Switzerland. This article is an open access article distributed under the terms and conditions of the Creative Commons Attribution (CC BY) license (https:// creativecommons.org/licenses/by/ $4.0 /)$.
Kinesiology Department, College of Health Sciences, Boise State University, 1910 University Avenue, Boise, ID 83725, USA; ShawnSimonson@BoiseState.edu; Tel.: +1-208-426-3973

\begin{abstract}
Environmental Physiology at Boise State University, Idaho, is a multidisciplinary course that expands students' understanding of human regulatory physiology through acute and chronic responses to environmental extremes. Students explore the physics (pressure, fluid dynamics, gas laws, sound, and light) of the underwater environment, marine flora and fauna adaptations to this environment, and the human experience within this environment. Included is completion of the Professional Association of Dive Instructors (PADI) Open Water Scuba Certification. The course culminates in an international dive trip where course concepts are further demonstrated and explored, and conservation activities are undertaken.
\end{abstract}

Keywords: active learning; experiential learning; evidence-based instructional practices; scuba diving; hyperbaric physiology

\section{Introduction}

I am slowly swimming in a clockwise circle at 22 feet. To my left, a great barracuda and Nassau grouper monitor my progress and the goings on inside the circle. To my right, a depression in the sand/grass ocean floor, maybe 20 feet across at a depth of 28 feet. I am off the reef at Flat Rock in the Exuma Keyes of the Bahamas and have just spotted my first lizardfish "standing" on the bottom-only to lose it. I had to look away from the lizardfish to find that I needed to retrieve a student diver who was having trouble clearing his ears and was spending a lot of energy in the first five feet of water. Other than the lizardfish, I have left nine other student divers in the depression. They are working on their open water dive skills, hovering, mask clearing, etc., with their instructor. I am their dive master, and I am monitoring those who are waiting their turn or have finished. This is their fourth dive, and other than the ear clearing issue, they have acquired their skills and I am spending most of my time swimming lazy circles monitoring them and checking out the sea grass, fairy basslets, yellowhead jawfish, and that barracuda and grouper.

"There's nothing wrong with enjoying looking at the surface of the ocean itself, except that when you finally see what goes on underwater, you realize that you've been missing the whole point of the ocean. Staying on the surface all the time is like going to the circus and staring at the outside of the tent."-Dave Barry.

Environmental physiology is the study of various factors affecting human performance and the subsequent adaptations of the body to changing environmental conditions [1]. Typical environmental conditions are temperature, humidity, air/gas concentrations, external pressure, and gravity. The physiological perturbations brought about by these environmental stressors can be used to enhance understanding of the physiological mechanisms that maintain homeostasis.

Active learning is "anything that involves students in doing things and thinking about the things they are doing" (p. 2) [2]. An intensive and potentially very effective variety of active learning is activity-based learning, which includes fieldwork [3]. Activity-based learning ties in-class work to out-of-class work and helps students learn through experience and reflect on that experience $[3,4]$. Fieldwork is often used as a teaching/learning 
strategy "to broaden, extend, and deepen the intellectual content by integrating theory and practice" (p. 166) [4]. It increases student motivation and knowledge application to enhance learning [4]. Table 1 outlines some of the strategies for effective fieldwork.

Table 1. Strategies for successful fieldwork experiences [4].

\begin{tabular}{|c|}
\hline Prior to Fieldwork \\
\hline $\begin{array}{l}\text { Make learning the main objective of fieldwork. } \\
\text { Establish specific learning objectives and build the experience around them. }\end{array}$ \\
\hline $\begin{array}{l}\text { Do the prework to prepare students for the experience. } \\
\text { Ensure that students know the underlying concepts } \\
\text { Use fieldwork to reinforce and go beyond the knowledge and skills developed in class }\end{array}$ \\
\hline $\begin{array}{l}\text { Connect fieldwork with academics. } \\
\text { Through fieldwork activities and reflections } \\
\text { Scaffold content and experiences if appropriate }\end{array}$ \\
\hline $\begin{array}{l}\text { Establish clear tasks and assignments for the students to accomplish in the field. } \\
\text { Scaffold content and experiences if appropriate } \\
\text { Create opportunities for deliberate practice of skills and abilities }\end{array}$ \\
\hline Establish clear guidelines as to what the student will do in the field. \\
\hline $\begin{array}{c}\text { Prompt student critical reflection. } \\
\text { Independently via a journal and/or } \\
\text { As a group via guided discussion or debrief } \\
\text { Timeliness is important and the sooner after the experience, the better }\end{array}$ \\
\hline $\begin{array}{l}\text { Require students to complete a journal (open format) } \\
\text { Record activities } \\
\text { Critically reflect on activities within the framework of the course. } \\
\text { Affectively reflect on activities } \\
\text { Provide specific prompts to aid reflection. } \\
\text { Encourage free-expression in addition to responding to prompts. }\end{array}$ \\
\hline Fieldwork Assessment \\
\hline $\begin{array}{l}\text { Require student self-assessment before, during, and after the fieldwork. } \\
\text { Provide prompts and/or a framework }\end{array}$ \\
\hline $\begin{array}{c}\text { Conduct ongoing reviews of the quality of the field experience. } \\
\text { Are the learning goals being met? } \\
\text { Are the desired connections being made? }\end{array}$ \\
\hline Assess academic work, not the experience \\
\hline Align assessment of student journals with the learning objectives. \\
\hline Provide students with multiple ways to demonstrate learning \\
\hline
\end{tabular}

The fieldwork experience is significantly improved when it is intentionally connected to the academic experience [3]. To realize this, the experience and the activities to be pursued must be carefully constructed around learning objectives and providing students opportunities to experience the desired activity. Connections between course content and the experience should be identified, and reflections about the experience are critical. Students should analytically and affectively reflect on the fieldwork and be provided with prompts that require them to intentionally observe and record the experience. The prompts should be clear to focus student attention and provide cues to collect the requisite information. The effectiveness of this is enhanced if students understand what they should be observing and how prior to doing so. Reflection should require students to not only observe, but also analyze the observations and identify underlying causes/reasons for what they experience and how it relates to other experiences within and outside of the fieldwork. In the successful fieldwork experience, the observations and relationships are intentionally linked back to the content area and academic experience [4]. 
Active learning and activity-based learning are facets of experiential learning, which is a holistic process that acknowledges and integrates behavior, thought, perception, and feeling [5]. The six principles of experiential learning theory are as follows: (1) Learning is a process of change rather than an acquisition of a skill or outcome that is (2) continuous and constructed around experiences because no one is a blank slate [5]. (3) Learning is motivated by the need to resolve tension created when there is a disconnect or disagreement between what is expected and what is experienced or observed, and that (4) all aspects of the holistic person (perception, feeling, thought, and behavior) will play a role in the resolution of the tension [5]. (5) The resolution of this conflict, learning, is transactional between the learner and the environment because both are changed as (6) the learner creates knowledge [5]. Thus, "learning is the process whereby knowledge is created through the transformation of experience" (p. 155) [5].

Active learning, including fieldwork, is a critical component of this environmental physiology course. Active learning provides an opportunity for all students to be involved and it keeps the majority from finding something else to attend to [2]. A bonus is that the class is more energetic and fun. Considerable research in cognitive science and the scholarship of teaching and learning have established that people will learn far more through active learning than from simply watching and listening to lectures [6]. Thus, little time is spent telling students what they need to know. Rather, they spend time discovering and constructing knowledge through activities that require them to read, think, solve, move, interpret, and do more than simply watch, listen, and take notes.

While an environmental physiology misconception study could not be found, in this author's experience, it seems that students have a number of misconceptions about physiological responses to the environment; for example, exaggerated benefits of training at altitude, minimized side effects of space flight, and the need for breath-holding during scuba diving. A benefit to teaching environmental physiology is that it provides ample opportunity to confront misconceptions, which is a goal of learning - the resolution of conflict between expectations and experience, or theories about what/why things happen and what actually happens [5]. The boundary between previous knowledge and new experiences must be explored, and this is where learning occurs [5]. Perhaps the most critical aspect of effective teaching is to help students with this process, to help with the formulation of new ideas, the resolution of conflict between experience and old ideas, and the reformulation of knowledge [5]. When David Kolb talked about learning being a transaction between the person and the environment, he was not specifically referring to the physical environment, but that interpretation is particularly applicable here. Kolb stated that the environment acts on the person, the person acts on the environment, and both are changed by objective conditions and subjective experience [5]. Experiential learning in environmental physiology is a concrete example of this phenomenon.

This paper describes the course, the rationale behind the course design, and the student-based outcomes of their participation. The question to be answered is, "Does using evidence-based instructional methods result in a transformative learning experience?".

\section{Methods}

\subsection{The Course}

KINES 511 Environmental Physiology is a graduate 3-semester credit course offered every 4th semester (fall of even years). In KINES 511, the focus is on the hyperbaric physiology component of environmental physiology. Instead of considering the variety of environmental factors in isolation, hyperbaric physiology is studied in detail because of the multisystem effects and the curiosity that many people have about the underwater world. On Earth, hyperbaric environments are found in sub-surface mines and construction as well as under water. Of these, water presents a greater hyperbaric stimulus and can be an interesting teaching tool for experiential learning. The classroom portion of this course is a multidisciplinary approach that focuses on the physics, comparative physiology, and the human response to increased pressure and temperature stress while the experiential portion 
focuses on students learning to function in the hyperbaric environment. Students earn their Professional Association of Dive Instructors (PADI) Open Water scuba certification in which they experience firsthand their own physiological and psychological responses to the hyperbaric environment and how to manage this exposure. An additional field experience portion of the course provides students with an opportunity for international travel and to use the scuba certification, refine their skills, and gain additional experience in the hyperbaric environment while enhancing their understanding of cultures outside of their own.

Process-Oriented Guided Inquiry Learning (POGIL) is a principal learning tool used in this course. The POGIL approach uses specially designed activities and cooperative learning to simultaneously introduce material and actively engage students in key processes, such as analytical thinking and working productively in a team [7]. Inquiry and cooperative learning strategies improve student achievement and problem-solving abilities more than the lecture format [8]. The POGIL approach is based on the benefits of inquiry and cooperative learning and that people learn through active involvement in the construction of their knowledge and understanding [9].

The focus of the course is on the application of the theories of physics and physiology, the rationale and research supporting these theories, and the ability to think critically about human exposure to various environments. Students learn to recognize, evaluate, and continue to learn and to make evidence-based decisions in physiology. Students also develop an understanding of the underwater world and scuba diving as they pertain to the physiology of exercise that enhances their ability as practitioners to understand and evaluate physiological information and help others improve their health, lives, performance, and achievement of their goals.

In the physics portion, students become familiar with the pressure, fluid dynamics, gas laws, and behavior of sound and light in the underwater environment. Comparative physiology, the analysis of marine flora and fauna adaptations to this environment, is briefly introduced to enhance understanding of the human response. Finally, the human experience within this environment is studied and experienced.

During the PADI course and the dive trip, students are prompted to focus on their physiologic and psychologic responses to the environment. Once students have the prior knowledge of physiological responses to the environment and learned to dive, each subsequent dive has a different objective beyond simply seeing what there is to see. Reflection prompts guide them to pay attention to particular physiologic and psychologic phenomena (Table 2).

Table 2. Phenomena to be observed during each dive.

\begin{tabular}{ccc}
\hline Dive Number & Physiologic Observation Prompt & Psychologic Observation Prompt \\
\hline 1. & Most incredible aspect of the experience. \\
2. & P phenomenon (hydration status) & Comfort/anxiety level \\
3. & Thermoregulation & Skill level/Room for improvement \\
4. & Buoyancy & Observation skills \\
5. & Gas behavior & Task loading \\
6. & Light and sound & Sensory responses/accommodations \\
\hline
\end{tabular}

Being that this is a graduate level course, assumed prior knowledge includes a basic understanding of:

- The energy systems utilized at rest and during physical exertion;

- The mechanism of muscle contraction;

- Muscle fiber types;

- Cardiovascular system function at rest and during exercise;

- Pulmonary system function at rest and during exercise;

- Short and long-term adaptations to physical activity; and

- The relationship between physical activity, fitness, nutrition, and weight control. 
Course learning outcomes are listed in Table 3.

Table 3. Fulfilling the promise in hyperbaric physiology (course outcomes).

At the Completion of This Course, the Student Will Be Able to:

Collaborate with others to observe, summarize, integrate, and appreciate the physiological systems:

Cardiovascular.

Pulmonary.

Neurovestibular.

Sensory.

Muscular.

Describe and apply the physics of hyperbaric environments

Predict and discuss the role of pressure in the underwater environment.

Understand and apply the gas laws to humans in a hyperbaric environment.

Observe, describe, and utilize the behavior of light and sound in air and water.

Describe flora and fauna adaptations/responses to the underwater environment.

Earn PADI Open Water scuba certification in order to experience firsthand their own physiological and psychological responses to the hyperbaric environment and how to manage this exposure.

Develop the knowledge to understand and apply the basic principles of scuba diving.

Learn and use basic scuba skills in a confined water environment.

Refine and further develop scuba skills in an open water environment.

Develop awareness and empathy for the aquatic environment and its inhabitants.

Identify personal lifestyle factors that impact the environment and the quality of life on our planet.

Demonstrate a commitment to living an environmentally healthy lifestyle.

Identify personal lifestyle factors that impact fitness, health, longevity, and quality of life. Demonstrate a commitment to living a healthy lifestyle.

Experience multiple learning modalities and determine effective tools for optimizing own learnings.

In the classroom, students learn the basics of large bodies of water, i.e., the characteristics of the different zones, before moving on to the pertinent physics. POGIL-based activities exploring the effects of temperature and pressure on gasses, effects of density on the behavior of light and sound, and buoyancy are completed.

Students then complete jigsaw activities and poster presentations describing and comparing the adaptations of the flora and fauna to include hydrodynamics, light (absence of, filtering of, wavelength spectrum) adaptations, pressure response mechanisms, and buoyancy control.

Additional POGIL-based activities are then used to study the human responses to immersion, light, sound, pressure, physical activity, temperature, and changes in psychology and decision making. The P phenomenon is used to explore fluid and temperature regulation [10]. Students' understanding of ventilation and its control is enhanced by considering pressure changes, diffusion, and the partial pressures of gasses. Laboratory activities demonstrate some of the physics principles, the effects of gravity and pressure when students measure blood pressure in different positions (including handstands), and the mechanisms of the dive reflex by putting their faces in buckets of ice water.

In addition to the culminating dive trip, field trips are the norm for this course. Four class meetings are held at the local dive shop to learn how to scuba dive. (Students tend to perform very well on the written exam as they have already learned the material at a much deeper level.) In addition, hyperbaric medicine is explored with a trip to the local wound and hyperbaric clinic.

The major writing assignment for the course challenges the creativity and problemsolving abilities of students. After students developed an understanding of the aquatic environment, how marine flora and fauna adapted to it, and the human response, they wrote an origin story for an aquaperson in which they explain the human physiological 
responses to hyperbaric environments and how a person might be modified to survive that environment sans equipment. The intent is that they demonstrate knowledge of the human response by identifying the problems and a knowledge of how other creatures had solved those problems in describing how the human could be altered to ensure survival beneath the open ocean. This assignment not only stretches their critical thinking abilities, but gives them a rare opportunity to be creative and write in a format different from what is typically required in graduate school.

An impactful series of assignments revolve around reading The Odyssey of KP2: An Orphan Seal and a Marine Biologist's Fight to Save a Species by Terrie Williams [11]. Dr. Williams' background in exercise physiology and the routine use of the same tools and concepts that are used in human performance to study marine mammals gives the students a glimpse of how their knowledge and skills could be used in a previously unexplored way. It also fits well with the flora and fauna jigsaws, as Williams describes physiological and behavioral adaptations of marine mammals to the hyperbaric aquatic environment. An added benefit is that it also presents a view of the complex relationship between people and the marine environment that we do not discuss in class. Students write weekly reflections as they read KP2. Many of the journal topics are about the application of the science, but a few consider other aspects of marine science and the interaction between humans and their world.

In addition to The Odyssey of KP2, PADI's Encyclopedia of Recreational Diving is the primary text and is supplemented with numerous research and review manuscripts from Undersea and Hyperbaric Medicine, Journal of Applied Physiology, and others [12].

\subsection{The Trip}

Most of the students complete their PADI open water dives on the dive trip. However, some are already certified or choose to complete their check-out dives locally. Due to the time of year, proximity, and available services, dive trips have been to the Caribbean. The dive operators have often worked with educational groups; however, none have reported experience with a human physiology-focused curriculum.

The main activities on the trips are open water scuba (Figure 1) and skin diving with further exploration of the physics, the flora and fauna, and the human responses to the hyperbaric environment. Balloons are inflated and diameters are measured at different depths. Water bottles and tennis balls are examined at different depths. Eggs are broken at 90 feet (for the advanced open water students) and 60 feet to observe how the pressure keeps them intact. Lights are used during night and day dives to observe the changes in color. Currents, waves, surge, and tides are experienced. Buoyancy is challenged, improved, and, in some cases, mastered. Students complete daily reflections during the trip to encourage application of the concepts, exploration of the content, and increased understanding of themselves.

\subsection{Course Assessment}

The number of students who have completed the course is relatively small, 43 , and the number who have made the dive trip is 29; thus, robust data collection is challenging. Online university-administered student course evaluations, Likert 5-point scale, and reflections during and after the course were used to obtain student feedback post-course. Data were combined for the four years that KINES 511 has been offered. Student course evaluation questions were grouped by theme (Table 4) and means and standard deviations were calculated [13]. Ranges are not reported because of the thematic grouping. The longer-term impact of the course was assessed during the summer of 2021 using a survey developed by Luetkemeier, Davis, and Hancock at Alma College and administered via Qualtrics. Institutional Review Board approval was obtained prior to survey administration and manuscript preparation. 


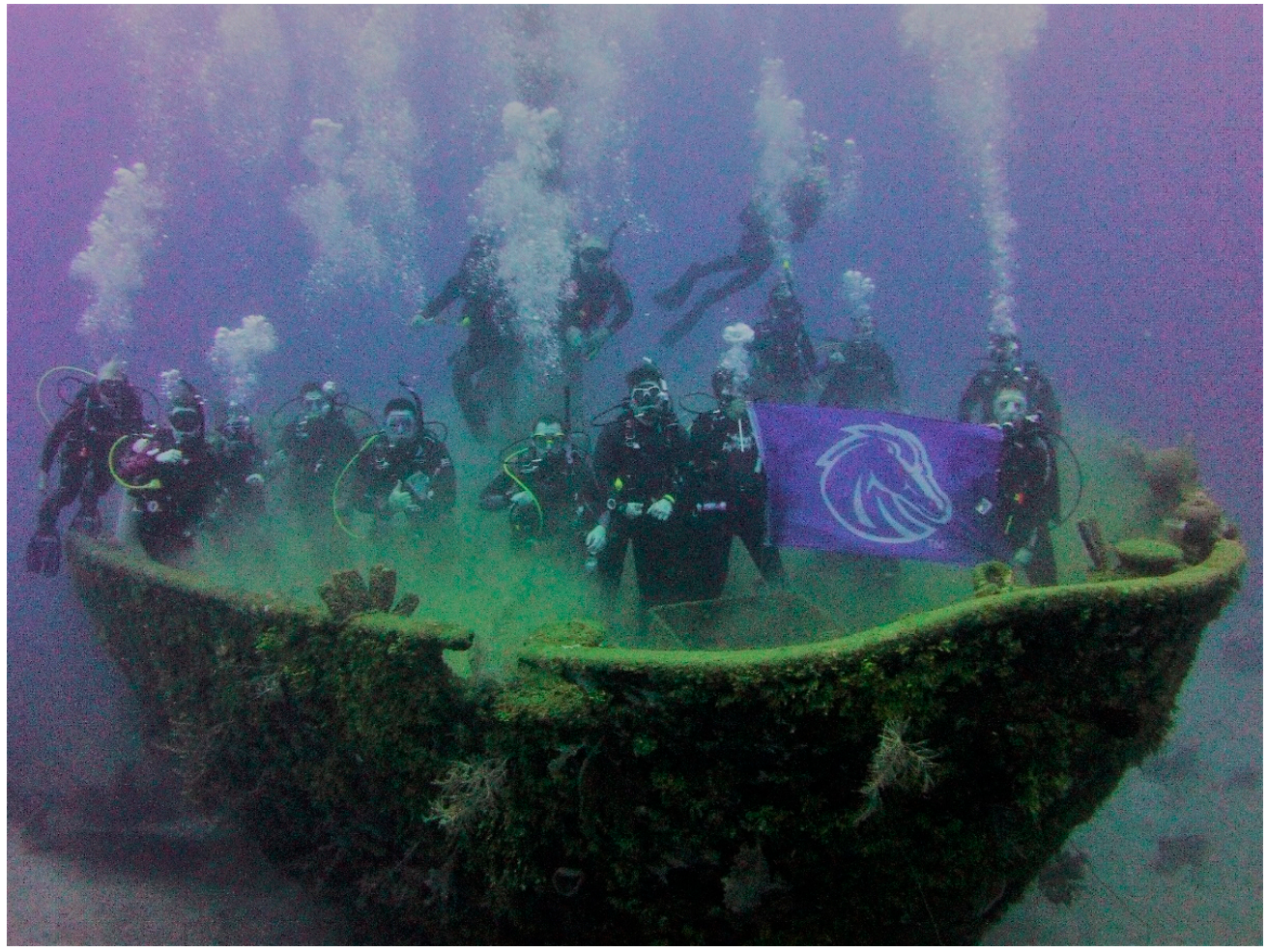

Figure 1. Class photo from one of the dive trips (date and location withheld to protect the identity of the course participants).

Table 4. Questions thematically combined from the student course evaluation responses.

\begin{tabular}{|c|}
\hline $\begin{array}{l}\text { Responsibility * } \\
\text { I Took Responsibility for My Own Learning. }\end{array}$ \\
\hline $\begin{array}{l}\text { Teaching Behaviors } \\
\text { The instructor seemed prepared for class. } \\
\text { The instructor fostered learning in this course. } \\
\text { The assessment methods were clearly explained. }\end{array}$ \\
\hline $\begin{array}{l}\text { Aquatic Awareness * } \\
\text { I have developed a greater awareness and empathy for the aquatic environmer } \\
\text { inhabitants. }\end{array}$ \\
\hline $\begin{array}{l}\text { PADI * } \\
\text { The PADI Open Water Scuba certification was a critical component of the } \\
\text { The PADI Open Water Scuba certification enhanced my understanding of cours }\end{array}$ \\
\hline $\begin{array}{l}\text { Enjoyed * } \\
\text { I enjoyed the course. }\end{array}$ \\
\hline $\begin{array}{l}\text { Course Content } \\
\text { The course materials made a valuable contribution to my learning. }\end{array}$ \\
\hline $\begin{array}{l}\text { Group Skills * } \\
\text { I have developed interpersonal and group interaction skills. }\end{array}$ \\
\hline $\begin{array}{l}\text { Learning * } \\
\text { I gained an understanding of the major concepts in this field. } \\
\text { I am able to apply the course content. } \\
\text { I tried to relate what I learned in this course to my own experiences. } \\
\text { I have improved my ability to analyze problems and think critically. } \\
\text { I have developed skills for life-long learning. }\end{array}$ \\
\hline
\end{tabular}


Table 4. Cont.

\section{Course Design}

Evaluation methods effectively measured mastery of the course objectives.

The objectives of the course were clearly explained.

I understood what was expected of me in this course.

There was agreement between course objective and what was taught.

The course material was relevant and meaningful.

The instructional style was effective for understanding concepts/developing skills.

The instructor challenged me to do my best work.

The instructor's method of evaluation (i.e., grading class projects, test) was fair.

* Instructor added questions. Those without the asterisk are standard student course evaluation questions. Questions pertaining to instructor behavior are not reported.

\section{Results}

Forty-three students enrolled in and completed KINES 511 in the fall of even years from 2014 to 2020. Dive trip locations were the Exuma Keys, Bahamas; Roatan, Honduras; and Cozumel, Mexico. Due to COVID-19, the 2020 class was significantly smaller and the dive trip was limited to a weekend at Homestead Crater in Midway, UT, USA. Student characteristics can be found in Table 5 (age is not available as these data were not collected during the course). Of the 43 students who completed KINES 511, two were certified divers prior to enrollment in the course, and 39 completed the PADI course work and pool sessions, 27 of whom completed certification during the course. Of the eight nonkinesiology undergraduate students, seven were biology majors and one was a psychology major. All of the non-kinesiology students were enrolled in 2016 and 2018. Of the five undergraduate alumni who responded to the survey, three were biology majors and two were kinesiology majors. The Luetkemeier, Davis, and Hancock survey was sent to the most recent email addresses of all 43 students who completed KINES 511 Environmental Physiology and 24 (56\%) responded.

Table 5. KINES 511 student characteristics.

\begin{tabular}{|c|c|c|c|c|c|c|c|}
\hline & Number $n(\%)$ & Female $n(\%)$ & Male $n(\%)$ & UG $n(\%)$ & $\mathrm{G} n(\%)$ & $\begin{array}{l}\text { Kinesiology } \\
\text { Major } n(\%)\end{array}$ & $\begin{array}{c}\text { Non-Kinesiology } \\
\text { Major } n(\%)\end{array}$ \\
\hline Total & $43(100)$ & $12(28)$ & $31(72)$ & $14(33)$ & $29(67)$ & $35(81)$ & $8(19)$ \\
\hline Trip & $31(72)$ & $10(83)$ & $21(51)$ & $13(93)$ & $17(59)$ & $23(66)$ & $7(88)$ \\
\hline Survey & $24(56)$ & $6(50)$ & $18(58)$ & $6(43)$ & $18(62)$ & $19(54)$ & $5(63)$ \\
\hline
\end{tabular}

$\mathrm{UG}=$ undergraduate students. $\mathrm{G}=$ graduate students.

In Table 5, "Total" is the total number of students enrolled in KINES 511 from 2014 2020 (four course offerings). Percentages in this row are based on the total number of students enrolled. "Trip" is the number of students who participated in the optional dive trip after the conclusion of the semester. Percentages in this row are based on the total number of students in the course that fit the same criteria, e.g., $83 \%$ of the females enrolled in the course went on the dive trip. "Survey" is the number of students who responded to the Luetkemeier, Davis, and Hancock survey. Percentages are based on the number of students in the course that fit the same criteria, e.g., $56 \%$ of the students enrolled in the course completed the survey.

\section{Student Course Evaluations and Survey Responses}

Of the 43 students, 31 (72\%) completed the university-administered online student course evaluations. Thematically combined student course evaluation data are presented in Table 6. Questions were grouped by theme (Table 4) and means and standard deviations were calculated. Ranges are not reported because of the thematic grouping. A score of 4 corresponds to agree and 5 to strongly agree. The range of means for the student course evaluation responses was 4.2-4.6, with an overall mean of $4.4 \pm 0.9$. The highest ranked 
response was students taking responsibility for their own learning at $4.7 \pm 0.9$. The lowest ranked response was course design at $4.2 \pm 0.8$.

Student comments:

"I believe the paper we had to write for this class foster my learning the most in this class. It made me develop a thorough understanding in order for me to describe the information accurately."

"It took it [the learning] outside the classroom and made it more engaging. Having something to relate to through direct experience made the material more applicable compared to simply having the information given."

Pertinent student responses to the end of course reflection assignment were thematically analyzed and grouped (Table 7). Some students provided more than one answer while others did not answer a particular question. The most frequent response (9/24, 38\%) to the question, "What was the greatest lesson learned about hyperbaric physiology?" related to the application of the concepts and experiencing/understanding the physiological responses. The application to medicine was the second most frequent response $(6 / 24,25 \%)$.

Table 6. Student responses to the KINES 511 student course evaluations.

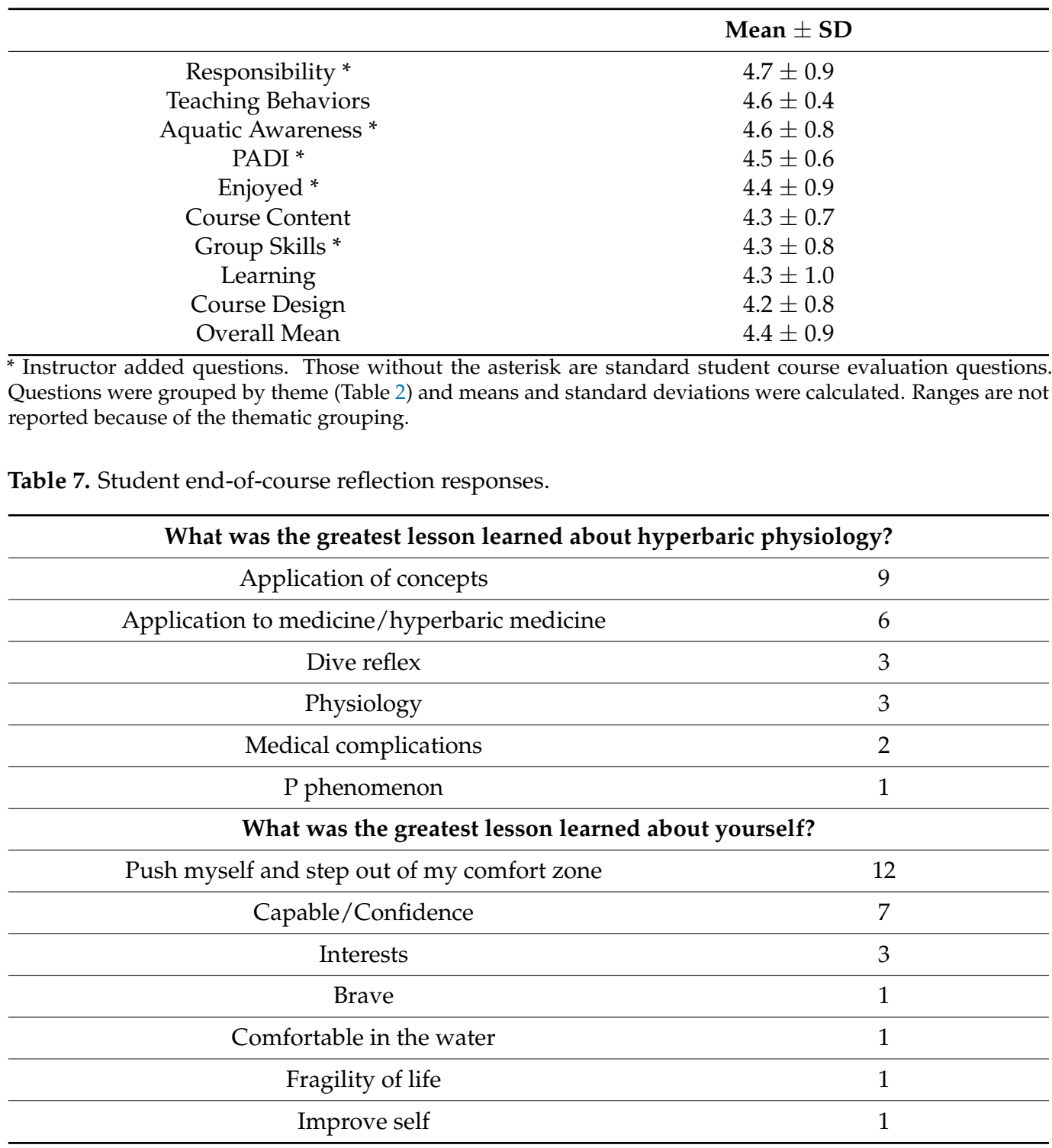


Table 7. Cont.

\begin{tabular}{|c|c|}
\hline Listen to constructive criticism & 1 \\
\hline Live and survive on the ocean & 1 \\
\hline Love people & 1 \\
\hline Make better choices about how I treat my body & 1 \\
\hline Not to judge a book by its cover & 1 \\
\hline Self-reflection as a tool & 1 \\
\hline \multicolumn{2}{|c|}{ In what ways did this class surpass your expectations? } \\
\hline Ocean content/Comparative Physiology & 10 \\
\hline Fun & 5 \\
\hline Applying knowledge & 4 \\
\hline Pedagogy & 3 \\
\hline Physiology content & 3 \\
\hline Scuba certification & 3 \\
\hline Travel & 2 \\
\hline Blackbeard Cruises & 1 \\
\hline Smaller close-knit group & 1 \\
\hline \multicolumn{2}{|c|}{ In what ways were you disappointed in this class? } \\
\hline NA & 9 \\
\hline Pedagogy (including more hands-on) & 5 \\
\hline Certification before dive trip (should have completed) & 1 \\
\hline PADI videos & 1 \\
\hline Too little human physiology & 1 \\
\hline Too little hyperbaric medicine & 1 \\
\hline Too little community service & 1 \\
\hline
\end{tabular}

Student comment:

"The application of all things learned in class were the greatest lessons. It was all necessary and awesome to see firsthand. How pressure changes with depth, how the body responds to the underwater environment through blood pressure, heart rate, plasma levels, hormones and baroreceptors. It was all such an amazing experience and to be able to experience those things was the ultimate lesson learned about hyperbaric physiology."

The most frequent response $(12 / 32,38 \%)$ to the question "What was the greatest lesson learned about yourself?" pertained to the students being pushed outside of their comfort zone and thriving. That they were capable and confident was the second most frequent response $(7 / 32,22 \%)$.

Student comment:

"I'm capable of so much more than I ever could have imagined."

The most frequent response $(10 / 32,31 \%)$ to the question "In what ways did this class surpass your expectations?" was the content pertaining to the ocean and comparative physiology. How much fun they had in the course was the second most frequent response $(5 / 32,16 \%)$. The most frequent response $(9 / 19,47 \%)$ to the question "In what ways were you disappointed in this class?" was none or not applicable. The pedagogy was the second most frequent response $(5 / 19,16 \%)$.

Student comments: 
"The comparative physiology aspect of the class surpassed my expectations. It is incredible how all species of animals share similar physiological responses and how all have adapted so specifically to the typical lifestyle of the species, so placing ourselves in 'their' world opened my eyes to the impressive adaptations of marine wildlife."

"I was a little disappointed with the confusing grading system and assignments at times, but aside from that it was a great experience!"

Of the 43 students, 24 (56\%) completed the 2021 follow-up survey. Figure 2 indicates the year that the survey respondents took the course; 2014 and 2018 are the most represented courses. Figure 3 indicates that the main reason $(20 / 24,83 \%)$ that the survey respondents chose to take the course was interest in the subject matter, with interest in travel being the second most frequent response $(14 / 24,58 \%)$. Of the 24 respondents, nine $(38 \%)$ indicated that the decision to take the course was also motivated by potential career choice, which, considering that Idaho is a landlocked state, is a bit surprising. That said, Figure 4 indicates that the course had a significant or somewhat positive impact on the survey respondents' choice of career more than half $(14 / 24,58 \%)$ of the respondents. Figure 4 also indicates that the course had a significant positive and positive impact on students' "overall understanding of physiology" (23/24, 96\%), "overall Boise State University experience" $(23 / 24,96 \%)$, and "aspiration for advanced education" (18/24, 75\%). Finally, Table 8 shows the ranking of Environmental Physiology as the students' favorite course and that it added to their college career at Boise State University.

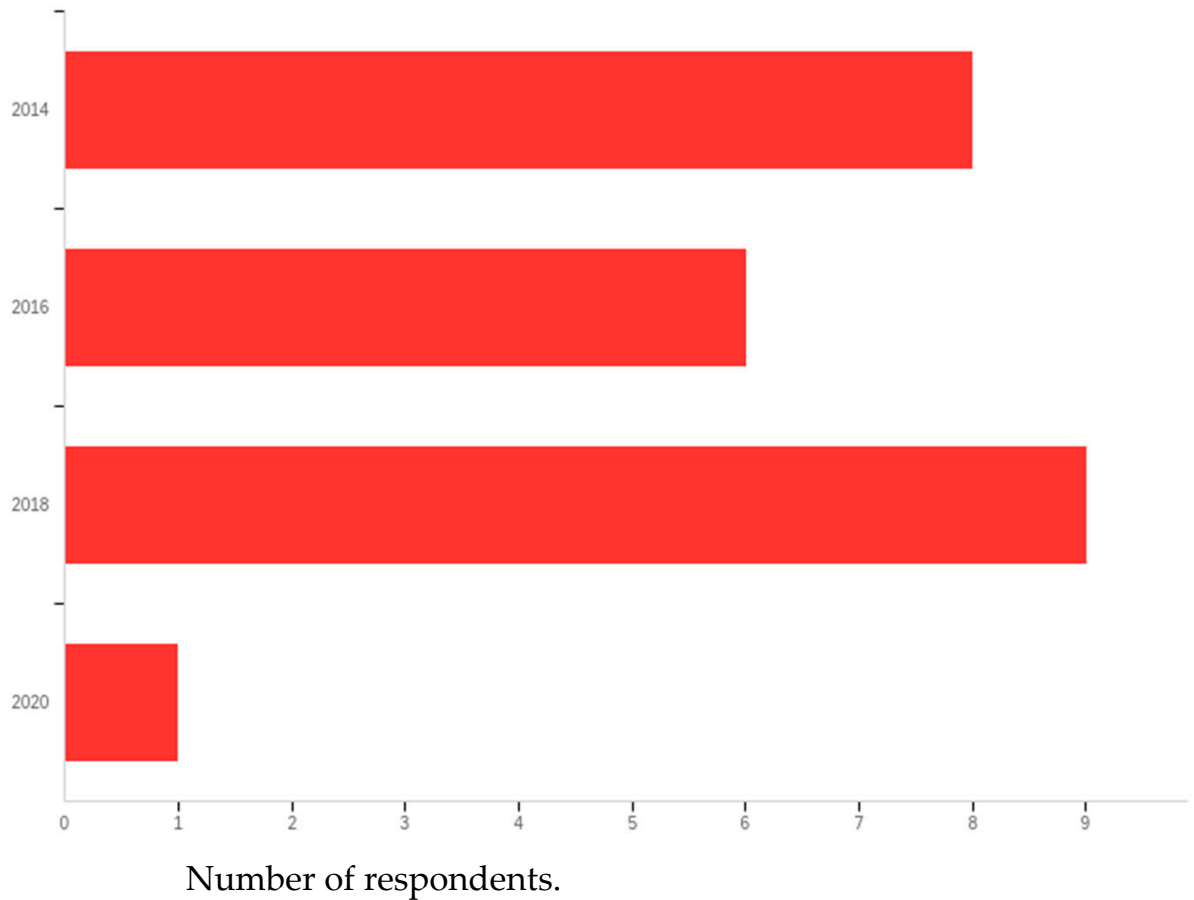

Figure 2. Select the year that you attended Environmental (formerly Hyperbaric) Physiology (KINES 511, formerly KINES 580). 


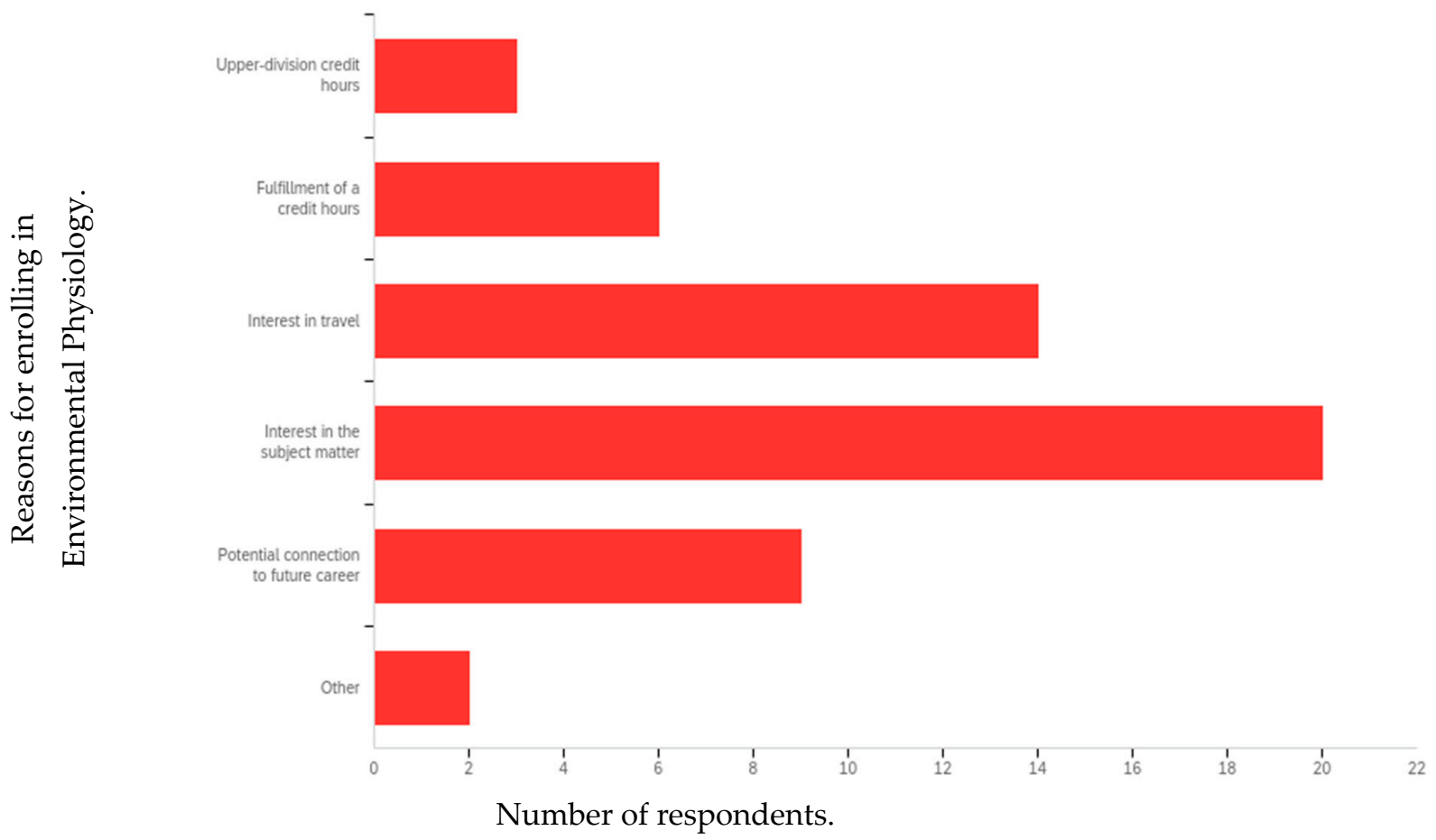

Figure 3. What prompted you to take Environmental Physiology? More than one choice is possible.

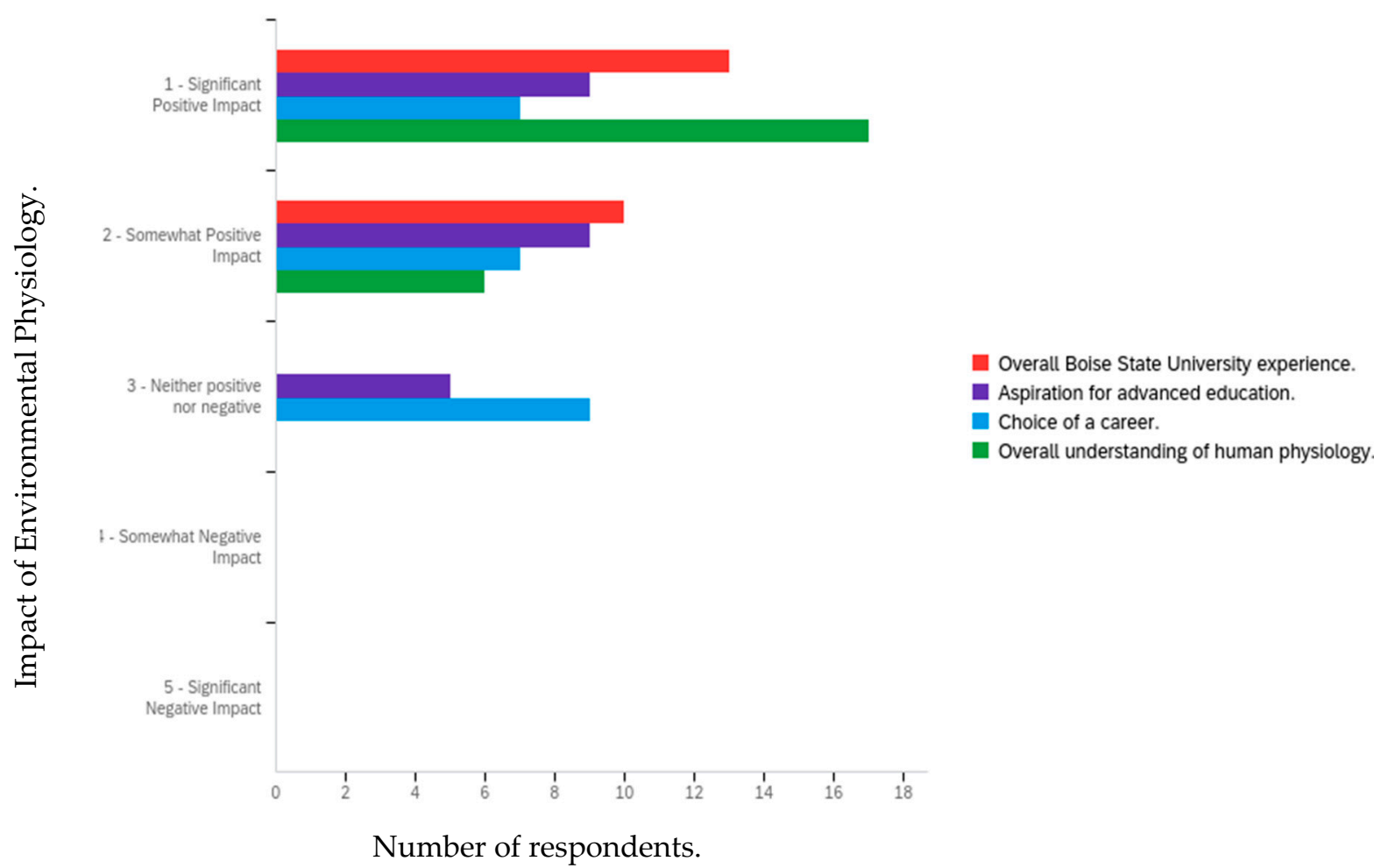

Figure 4. On a scale from 1-5, with $1=$ significant positive impact and $5=$ significant negative impact, what level of impact did Environmental Physiology have on your overall Boise State University experience, aspiration for advanced education, choice of a career, and overall understanding of human physiology? 
Table 8. Student responses to the KINES 511 survey questions.

\begin{tabular}{ccc}
\hline Question & Min/Max & Mean \pm SD \\
\hline $\begin{array}{c}\text { On a scale from 1-5, with 1 = one of my least favorite classes } \\
\text { and 5 = one of my most favorite classes, how would you } \\
\text { rank Environmental Physiology with other classes that you } \\
\text { took in college? }\end{array}$ & $4 / 5$ & $4.6 \pm 0.5$ \\
\hline $\begin{array}{c}\text { On a scale from 1-5, with 1 = added very little and } \\
\text { 5 added a lot, how did experiential learning classes such } \\
\text { as Environmental Physiology add to your college career? }\end{array}$ & $3 / 5$ & $4.6 \pm 0.6$ \\
\hline
\end{tabular}

\section{Student responses:}

"The trip with environmental physiology class was a great ending to my time at BSU. Additionally, it was a great course on physiology that helped me throughout medical school."

"College was/is about intellectual formation and this course was one of the best, therefore, it added to my college career greatly."

"I remember what I learned more than a lot of other courses due to the hands-on learning."

"I think it added quite a bit to my college career because I would have never pursued learning about environmental factors and how they pertain to the human body and exercise. I was able to be thrown into a new subject that actually has a lot to do with exercise not in the weight room like hiking, diving, camping at altitude, etc. I also am able to say I tried something I never would have without this class."

"It was beyond helpful. I've been able to better connect with patients in the clinical setting. The experimental learning was huge. Actually using and immersing ourselves in the content was something very few people get to experience. This course is set apart from many of the others in my education. One that added exponentially more positive benefits to my life than I ever thought possible. I hope they keep this going!"

"The learning was hands-on, applied on the trip and captivating-don't get me wrong, it was definitely hard, but the material kept my attention and encouraged me to broaden my knowledge regarding the human body and its processes."

\section{Discussion}

It is difficult to compare student course evaluation (Likert scale) data to other courses as some ratings may include error from mismarks, misreads, or less-than-optimum sampling and are not precise [14]. Statistically significant differences between courses can also not be identified as standard deviations, errors, or confidence intervals were not reported for other department courses and class size is highly variable [14].

The follow-up survey results need to be taken with a grain of salt as it is assumed that those students who enjoyed the course were more likely to respond to the survey. We also do not know how many former students were not reached due to out-of-date or incorrect email addresses. With this in mind, a response rate of $56 \%$ is quite satisfactory.

With those two caveats, it does appear that KINES 511 Environmental Physiology has had a positive impact on the education and lives of the enrolled students. This ties directly to why many of us teach-because we want to positively impact the lives of others. We wish to create an experience that will change a student's life.

As educators, then, we might want to increase the likelihood of learning by creating a life-changing event through positive tension, encouraging reflection, and providing an alternate behavior, which we can term high-impact educational practices [15]. Highimpact practices are instructional practices for which evidence suggests that they are 
likely to work in most learning situations [16]. In a 2013 report, the American Association of Colleges and Universities (AAC\&U) identified ten pedagogies that tend toward the highest impact $[15,17]$. Of these, Environmental Physiology incorporated collaborative assignments and projects, global learning, and a project that integrated and applied what was learned. Based on the post-course surveys, it appears that this course was of both high and long-term impact.

When viewed from a physiological perspective, adaptation is a change in the response to a stimulus. From a behavioral perspective, this same definition can be used for learning [18]. There is potential for adaptation and learning whenever there is a disruption of homeostasis or the status quo. From a cognitive perspective, the difference is that in learning, there needs to be a reasoned response [18]. Learning requires that the learner recognizes a tension or a disconnect between what they are actually experiencing and what they expect to experience [18]. Even with this tension, learning, or change, is not certain and reflection must occur to identify and resolve the tension and decide upon a subsequent behavior change $[5,18]$. However, according to experiential learning theory, learning is not simply behavioral or cognitive-it is a holistic process, because there are the filters of perception and feeling in addition to thought and behavior, all of which must be considered and integrated [5]. The reflections throughout the course, dive trip, and after the course appear to have enabled learning and adaptation to occur.

The use of learner-centered pedagogical tools such as POGIL, experiential learning, and reflection created a tension through novel methods and increased student responsibility and accountability. The addition of the PADI open water scuba certification and international dive trip provided additional potential for a transformative experience. Required guided reflections helped to complete the learning cycle, and from the account of the students who completed the student course evaluations and follow-up survey, a transformation was accomplished. The transformation ranged from developing a new perspective to life-altering.

The motivation for and processes of learning change with the circumstances and as we mature [5]. Upper division and college graduate students either are, or are transitioning to becoming, adult learners [19]. According to the theory of andragogy, adult learning is enhanced when learners understand why they need to learn something, learn experientially, approach learning as problem-solving, and when the content is immediately valuable [20]. Thus, graduate education should endeavor to accomplish as many of these four criteria as possible to optimize learning, and experiential learning is a reliable vehicle to this end.

Experiential learning is based on the tenets of several other theories [5]. Concrete experience leads to the formulation of concepts. Subsequent experiences then provide opportunities to test and validate those concepts based on the feedback provided by the experience and others who share the experience [5]. Beyond this, there is a need to reflect on the experience and feedback to modify or change the concept and shape future responses [5]. This process of experience, concept development, concept testing, reflection, revision, and purposeful responses changes across time as one ages and gains experience, from concrete to more abstract [5].

Thus, the success of Environmental Physiology lies in requiring the four learning abilities that are cyclical in their application: (1) concrete experience-being fully, openly, and without bias, involved in new experiences; (2) reflective observation-reflect on experiences and observations from multiple perspectives; (3) abstract conceptualizationcreate concepts to integrate observations into "logically sound theories"; and (4) active experimentation-using the theories to make decisions and solve problems (p. 148) [5]. Opportunities are provided for students to be successful learners by requiring the ability to be both an actor and observer as well as both involved and detached in the process [5]. "Learning is the major process of human adaptation" (p. 149) [5]. 


\section{Moving Forward: Course Changes to Be Implemented}

In response to the student feedback, a few changes will be made to the course. While the pedagogy and assessments will not be changed, communicating the evidence behind the decisions to make these instructional choices will be enhanced. Explicitly modeling the use of evidence to make decisions may improve student understanding and acceptance of those decisions. We will also explore more active learning strategies to increase the use of experiential learning to replace classroom activities, i.e., the use of computer simulations to explore the physics portion of the course.

\section{Conclusions}

As in the Dave Barry quote at the beginning of this manuscript, not only do students explore what "goes on underwater", they also explore gain a deeper understanding of how the human body responds to environmental extremes and to find out more about what is beneath their own surface. It appears that, based on student feedback, using evidence-based instructional methods does result in a transformative learning experience.

"This class will make you work hard, push your limits, and make you try things you've never thought of doing before, but it will be SO rewarding in the end. I never thought that I would be able to apply doing a handstand and taking blood pressures simultaneously to hyperbaric physiology, but it all made sense. The class exercises seem silly, like sticking your face in water, but they all connect. And when it finally clicks: you will feel like a rock star."

Funding: This research received no external funding.

Institutional Review Board Statement: The study was conducted according to the guidelines of the Declaration of Helsinki, and approved by the Institutional Review Board of Boise State University (protocol code 186-SB21-065, 2 April 2021).

Informed Consent Statement: Informed consent was obtained from all subjects involved in the study.

Data Availability Statement: The data presented in this study are available on request from the corresponding author. The data are not publicly available due to the potential for eliminating participant anonymity.

Acknowledgments: The author acknowledges Dive Magic, Boise, ID, for their enthusiastic aid in developing and offering this course; St. Luke's Wound and Hyperbaric Clinic, Meridian, ID, for their ongoing support and shared educational experience; Global Learning Opportunities at Boise State University for their incredibly valuable logistical support in offering the international dive trips; and last, and by no means least, the students for helping to create a successful learning experience for themselves, their peers, and their instructor.

Conflicts of Interest: The authors declare no conflict of interest.

\section{References}

1. Pandolf, K.B.; Sawka, M.N.; Gonzalez, R.R. Human Performance Physiology and Environmental Medicine at Terrestrial Extremes; Cooper Publishing Group: Traverse City, MI, USA, 1988.

2. Bonwell, C.C.; Eison, J.A. Active Learning: Creating Excitement in the Classroom; Office of Educational Research and Improvement: Washington, DC, USA, 1991.

3. Lang, J.M. Small Teaching: Everyday Lessons from the Science of Learning; Jossey-Bass: San Francisco, CA, USA, 2016 ; p. 259.

4. Davis, B.G. Tools for Teaching, 1st ed.; Josey-Bass: San Francisco, CA, USA, 1993; p. 429.

5. Kolb, D.A. The process of experiential learning. In Culture and Process of Adult Learning; Thorpe, M., Edwards, R., Hanson, A., Eds.; Routledge: London, UK, 1993; pp. 138-156.

6. Freeman, S.; Eddy, S.L.; McDonough, M.; Smith, M.K.; Okoroafor, N.; Jordt, H.; Wenderoth, M.P. Active learning increases student performance in science, engineering, and mathematics. Proc. Natl. Acad. Sci. USA 2014, 111, 8410-8415. [CrossRef] [PubMed]

7. Bauer, C.F.; Daubenmire, P.L.; Minderhout, V. Not just a good idea, POGIL has a theoretical foundation. In POGIL: An Introduction to Process Oriented Guided Inquiry Learning for Those Who Wish to Empower Learners; Simonson, S.R., Ed.; Stylus Publishing, LLC: Sterling, VA, USA, 2019; pp. 3-22. 
8. Lo, S.M.; Mendez, J. L: Learning-The evidence. In POGIL: An Introduction to Process Oriented Guided Inquiry Learning for Those Who Wish to Empower Learners; Simonson, S.R., Ed.; Stylus Publishing, LLC: Sterling, VA, USA, 2019; pp. 85-112.

9. Simonson, S.R.; Shadle, S.E. Implementing Process Oriented Guided Inquiry Learning (POGIL) in undergraduate biomechanics: Lessons learned by a novice. J. STEM Educ. 2013, 14, 56-63.

10. Bookspan, J. Diving Physiology in Plain English; Undersea and Hyperbaric Medical Society, Inc.: Kensington, MD, USA, 1997; p. 246.

11. Williams, T.M. The Odyssey of KP2: An Orphan Seal and a Marine Biologist's Fight to Save a Species; Penguin Books: New York, NY USA, 2013; p. 304.

12. Richardson, D.; Kinella, J.; Shreeves, K. Encyclopedia of Recreational Diving; PADI, Inc.: Rancho Santa Margarita, CA, USA, 2005.

13. Carifio, J.; Perla, R. Resolving the 50-year debate around using and misusing Likert scales. Med Educ. 2008, 42, 1150-1152. [CrossRef] [PubMed]

14. Franklin, J. Interpreting the numbers: Using a narrative to help others read student evaluations of your teaching accurately. New Dir. Teach. Learn. 2001, 87, 85-100. [CrossRef]

15. Kuh, G.D. High-Impact Educational Practices: What They Are, Who Has Access to Them, and Why They Matter; Association of American Colleges \& Universities: Washington, DC, USA, 2008.

16. Department of Education and Training. High Impact Teaching Strategies-Excellence in Teaching and Learning; Department of Education and Training, Ed.; State of Victoria: Melbourne, Australia, 2017; p. 32.

17. AAC\&U. High-Impact Educational Practices: A Brief Overview: Association of American Colleges \& Universities. 2013. Available online: https:/ / www.aacu.org/node/4084 (accessed on 30 July 2021).

18. Schunk, D.H. Learning Theories: An Educational Perspective; Pearson, Inc.: Hoboken, NJ, USA, 2020; p. 608.

19. Adult learner [Internet]. IGI Global. 2021. Available online: https://www.igi-global.com/dictionary/postsecondary-programdesign-for-adult-learners/711 (accessed on 22 June 2021)

20. Knowles, M.S. Adragogy: Adult Learning Theory in Perspective. Community Coll. Rev. 1978, 5, 9-20. [CrossRef] 